\title{
Off - Line Optimization of Strategic and Design Parameters of a Hybrid Stand-Alone Wind/Solar/Fuel Cell/Battery System
}

\author{
Soumyadeep $\mathrm{Nag}^{1}$, Namitha Philip ${ }^{2}$ \\ ${ }^{1}$ (Department of EEE, SRM University, India) \\ ${ }^{2}$ (Department of EEE, SRM University, India)
}

\begin{abstract}
Energy management strategy governs the performance and efficiency of the system. This paper reports the use of an innovative strategy that implements monthly power split parameters to decide the division of load between the fuel cell and the batteries. These parameters are optimized and derived from swarm intelligence during the optimal sizing of a wind/PV/battery/Fuel cell configuration along with the optimized numbers of solar panels, wind turbines, fuel cells, batteries, DOD of batteries and the amount of hydrogen storage requirement. The energy management strategy also divides the operation of the system into five modes. While wind and solar form the primary sources of energy, batteries and a fuel cell stack forms the secondary and primary back-up source respectively. Two parameters, expected value of energy not served and the per-unit cost, have been chosen for the justification of the most optimal configuration. An adaptive particle swarm optimization is used for optimal sizing and a couple of radial basis neural networks trained with reset particle swarm optimization are used to calculate the life of batteries and fuel cell under specific operating conditions, thus helping us to maximize the life of fuel cells.
\end{abstract}

Keywords: Hybrid renewable energy systems; Energy management strategy; Adaptive particle swarm optimization; Reset Particle swarm optimization; Radial Basis Function Network; life of batteries and fuel cells; Optimal Sizing; Hybrid back-up management

\section{Introduction}

Hybrid energy sources are now entering every energy market in the world due to their enhanced reliability and ability to cope up with varying weather conditions. Wind and solar are complementary sources of energy and a hybrid system improvises upon the intermittency by using energy storage facilities. Focused research on energy storage sources has lead to the reduction of cost of fuel cells, Electrolyzers and batteries. The hybrid energy system presented in this paper consists of solar panels, wind turbines, batteries and a PEM fuel cell. This paper also concentrates on swarm intelligence as it compares the performance of two variants of PSO: RPSO and APSO to achieve two different tasks a) optimal sizing b) neural network training.

The techno-economic problem of optimal sizing has been solved by many scholars in different ways using different tools as mentioned in the literature. In [1] a hybrid simulated annealing - taboo search method for optimal sizing for autonomous power system is presented where various constraints like initial cost, unmet load, and operational constraints like battery set point for diesel generator charging etc. have been considered. Similar works have been performed in $[2,3,4,5]$. In [6] optimal sizing has been performed for a wind/PV/battery system using an improved PSO which introduces the concept for reset and disturbance in PSO. [6] also reports the use of LPSP to measure systems reliability. In [7] genetic algorithm is used for solving the problem. In [8] authors have proposed a unique standalone hybrid wind solar power generation system, which is characterized by PLL control and dump power control. They have also proposed that the requirement of a high speed dedicated communication line will not occur and neither will there be any requirement for dump load or dump load control. There are several parameters used to judge a combination, where in the literature LPSP, LCE and ACS are among the main parameters that are used [11, 12, 13]. An hourly basis analysis has been performed, instead of a monthly average method [9] or a worst month method [10], which helps to avoid over sizing. The use of hybrid power storage has recently become a key area of research. In this work, the main purpose of using a hybrid storage system is to elongate the life of the major storage element (Fuel cell stack). Another reason for supporting the fuel cell with the battery bank is to enhance its dynamic response [14]. In comparison to commonly used battery storage, $\mathrm{H}_{2}$ is well suited for seasonal changes, because of its inherent high mass energy density and longevity of energy storage (compared to batteries). Using Hydrogen fuel can result in freedom in economy as dependency on fossil fuels will reduce as a result of which cost economic fluctuations can be reduced.

Fig. 1 describes the system that has been dealt with in this paper. An innovative energy management strategy has been designed to reduce the reliability and the per-unit cost of the system. The energy management strategy divides the operation of the system into five different modes: a) Battery mode b) Fuel cell mode c) Fuel cell recharge mode d) Hybrid mode and e) Renewable recharge mode. The strategy utilizes the power split 
parameter that has been derived from APSO during hybrid mode of operation. The optimal sizing not only includes this energy management strategy but it also aims to extend the life of the major storage element which, in this case, is the fuel cell. In order to accomplish this task it involves a couple of radial basis function neural networks which have been trained with RPSO to decipher the life of batteries or the fuel cell respectively.

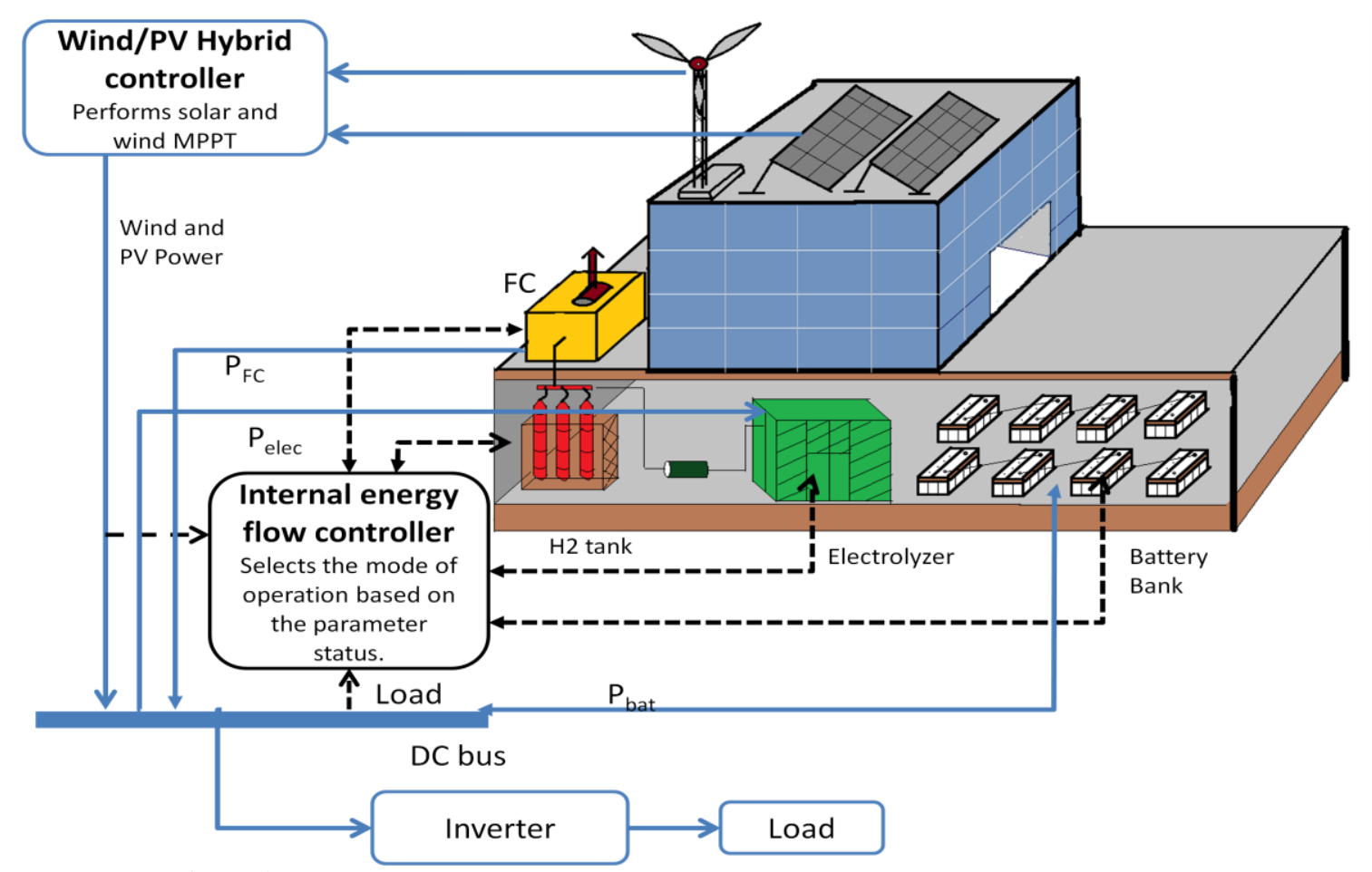

Figure1. Solar/Wind /Battery bank/FC combination along with the control strategy

\subsection{Modeling of solar modules}

\section{Modeling of components of the hybrid energy system}

Kyocera's KC200GT has been used in this paper. Like all semi conductor devices, solar cells are also affected by temperature. Any increase in temperature causes a reduction in band gap, hence causing an increase in dark current [15]. The importance of LF has been realized in [16, 17], where different kinds of dust have been deposited over the solar panels (ash, red soil, etc). As a result of dust accumulation, open circuit voltage has been observed to undergo a reduction of $5 \%$ to $25 \%$ [16]. The main equation giving the steady state power of a solar panel is given as follows:

$\mathrm{PPV}=\mathrm{P}_{\mathrm{N}} \cdot \mathrm{G}_{\mathrm{t}}\left(1-\left(\frac{\mathrm{C}_{\mathrm{t}}}{100(\mathrm{TC}-\mathrm{TN})}\right)\right) \mathrm{NS} \cdot \frac{\mathrm{NP}}{\mathrm{LF}} \cdot$ effinv

Where, $\mathrm{P}_{\mathrm{N}}$ is the nominal power, $\mathrm{G}_{\mathrm{t}}$ is the hourly radiation, TC is the cell temperature, NS and NP are the no. of modules in series and parallel and LF is the loss factor which takes care of the effects of dust accumulating on the surface of the panel. LF is usually in the range of 1.1 to $2 . \mathrm{C}_{\mathrm{t}}$ is the temperature coefficient of the panel, TC is the Cell temperature, $\mathrm{TN}$ is the nominal cell temperature,

The cell temperature is calculated by using:

$\mathrm{TC}=\mathrm{T}_{\mathrm{amb}}+\frac{\mathrm{G}(\mathrm{NCOT}-20)}{800}$

Where, $\mathrm{T}_{\mathrm{amb}}$ is the ambient temperature, $\mathrm{G}$ is the radiation in $\mathrm{W} / \mathrm{m}^{2}$ and NCOT is the normal cell operating temperature. NCOT is the normal cell operating temperature which is fixed to $47^{\circ} \mathrm{C}$. Cell temperature plays an important role as:

$\frac{1}{\mathrm{P}_{\mathrm{M}}} \frac{\mathrm{dP}_{\mathrm{M}}}{\mathrm{dT}} \sim-(0.004$ to 0.005$)$ per $^{\mathrm{O}} \mathrm{C}$ for $\mathrm{Si}$

where, $\mathrm{P}_{\mathrm{M}}$ is the Power at maximum power point. The solar modules that have been used here are rated $200 \mathrm{~W}$, $24 \mathrm{~V}$, so NS has been fixed to 2, while NP has been considered a design variable for optimization. 


\subsection{Modeling of wind turbines}

The amount of mechanical power captured by a wind turbine from the wind is a function of the area (A) swept by its blades, air density $\rho$, the incoming wind velocity ( $v$ )and its conversion efficiency $\mathrm{C}_{\mathrm{p}}$. The conversion efficiency or power coefficient of a turbine $\mathrm{C}_{\mathrm{p}}$ is a function of the tip-speed ratio $\lambda$ and pitch angle $\beta$. The general equation for wind power is given as [18]:

$\mathrm{P}_{\mathrm{WT}}=.5 \mathrm{C}_{\mathrm{p}}(\lambda, \beta) \rho(\mathrm{T}) \mathrm{AV}^{3}$

Where, $\lambda$ is the ratio of the tip speed of the turbine blades to wind speed. Mathematically:

$\lambda=\frac{\omega_{\mathrm{m}} \mathrm{R}}{\mathrm{v}}$

Since the data of rotational speed is not in hand, the coefficient of power extraction has modeled with the following function to match that provided in the user manual [18]:

$\mathrm{C}_{\mathrm{p}}=\sum_{\mathrm{i}=0}^{9} \mathrm{P}_{\mathrm{i}} \mathrm{x}^{\mathrm{i}}$

Table 1. Value of Pi for the ten coefficients

\begin{tabular}{|l|l|l|l|l|l|l|l|l|l|}
\hline $\mathbf{P}_{\mathbf{0}}$ & $\mathbf{P}_{\mathbf{1}}$ & $\mathbf{P}_{\mathbf{2}}$ & $\mathbf{P}_{3}$ & $\mathbf{P}_{4}$ & $\mathbf{P}_{5}$ & $\mathbf{P}_{6}$ & $\mathbf{P}_{7}$ & $\mathbf{P}_{8}$ & $\mathbf{P}_{9}$ \\
\hline $2 \mathrm{e}-9$ & $2 \mathrm{e}-7$ & $-9 \mathrm{e}-6$ & $.2 \mathrm{e}-5$ & $-34 \mathrm{e}-5$ & $.031 \mathrm{e}-3$ & -.1729 & .49 & -.437 & .013 \\
\hline
\end{tabular}

Where, $P_{i}$ is the coefficient of $x^{i}, \omega_{m}$ is the turbine rotational speed in mechanical radians/second and $R$ is the radius of the turbine in meters. Table 1 presents the values of $P_{i}$. While extracting the maximum power from the turbine, the value of the pitch angle $\beta$ is kept constant (around 0 ), to ensure maximum possible turbine output. The wind turbine that has been considered is a Bornay 6000 rated, $48 \mathrm{~V}$ DC at $6 \mathrm{KW}$.

\subsection{Modeling of fuel cells}

Fuel cells are electrochemical devices that convert gaseous fuel directly into electricity. Proton exchange membrane fuel cell can be operated at low temperature (about $80^{\circ} \mathrm{K}$ ) and thus can be used domestically. A fuel cell consists of an electrolyte sandwiched between two electrodes. The electrolyte has a special property that allows positive ions (protons) to pass through while blocking electrons. Hydrogen gas passes over the anode and with the help of a catalyst, separates into electrons and Hydrogen protons.

Anode reaction:

$2 \mathrm{H}_{2}=>4 \mathrm{H}^{+}+4 \mathrm{e}^{-}$

Cathode reaction:

$\mathrm{O}_{2}+4 \mathrm{H}^{+}+4 \mathrm{e}^{-}=>2 \mathrm{H}_{2} \mathrm{O}$

Overall reaction:

$2 \mathrm{H}_{2}+\mathrm{O}_{2}=>2 \mathrm{H}_{2} \mathrm{O}$

To model the steady state characteristics of the PEMFC, a detailed model [19], using the details in the user manual, has been simulated and the results of power output have been plotted along with the consumption of Hydrogen and efficiency of the device. Piece-wise Curve fitting is then performed and A \& B coefficients have been derived. The steady-state fuel cell system modeling has been performed with the help of A, B constants as follows:

$$
\begin{array}{ll}
\operatorname{cons}_{\mathrm{fC}}=\mathrm{A}_{\mathrm{FC}} \cdot \mathrm{P}_{\mathrm{N}_{\mathrm{FC}}}+\mathrm{B}_{\mathrm{FC}} \cdot \mathrm{P} & \text { if } \mathrm{P}_{\text {output }}<\mathrm{P}_{\max \text { igeff }} \\
\text { cons }_{\mathrm{fC}}=\mathrm{B}_{\mathrm{FC}} \cdot \mathrm{P}_{\mathrm{N}_{\mathrm{FC}}}+\mathrm{A}_{\mathrm{FC}} \cdot \mathrm{P}\left(1+\mathrm{F}_{\mathrm{ef}}\left(\frac{\mathrm{P}}{\mathrm{P}_{\mathrm{N}}}-\frac{\mathrm{P}_{\mathrm{max}} \text { eff }}{100}\right)\right) & \text { if } \mathrm{P}_{\text {output }}>\mathrm{P}_{\max \text { 区eff }}
\end{array}
$$

Where, $\mathrm{A}_{\mathrm{FC}}$ (equal to $.05 \mathrm{Kg} / \mathrm{KW}$ ), $\mathrm{B}_{\mathrm{FC}}$ (equal to $.004 \mathrm{Kg} / \mathrm{KW}$ ) are the Power coefficients for the fuel cell, $\mathrm{P}_{\text {max _eff }}$ is the rated power output of fuel cell at maximum efficiency, $\mathrm{P}_{\text {output }}$ is the output power of the fuel cell, $\mathrm{F}_{\mathrm{ef}}$ is the faraday's efficiency, $\mathrm{P}$ is the power to be supplied by the fuel cell, $\mathrm{P}_{\mathrm{Nfc}}$ is the nominal rating of the fuel cell, cons $_{\mathrm{fc}}$ is the consumption of hydrogen. 


\subsection{Modeling of batteries}

The steady state model of a battery is concerned only with the state of charge (SOC) of the battery [20, 21]. An alternate means of describing the condition or health of the battery is the DOD. The change in SOC is given by the as:

$\operatorname{SOC}(\mathrm{t}+\Delta \mathrm{t})=\operatorname{SOC}(\mathrm{t}) \cdot(1-\delta)+\mathrm{I}_{\text {bat }}(\mathrm{t}) \Delta \mathrm{t} \eta_{\mathrm{t}}$

Where,

$I_{\text {batmax }}(t+\Delta t)=\max \left[0, \min \left\{I_{\max },\left(\frac{c}{\Delta t} \operatorname{SOC}_{\max }-\operatorname{SOC}(t)\right)+\left(S O C-S_{\text {SOC }}\right.\right.\right.$ min $\left.\left.) \frac{1-c}{\Delta t}\right\}\right]$

And,

$\mathrm{C}=\left\{\begin{array}{l}1 \text { battery is charging } \\ 0 \text { battery is disc harging }\end{array}\right.$

$\mathrm{SOC}_{\max }=\mathrm{N}_{\text {batp }} \mathrm{C}_{\mathrm{N}}$

$\mathrm{SOC}_{\min }=\mathrm{N}_{\text {batp }} \mathrm{C}_{\mathrm{N}}(1-\mathrm{DOD})$

Where, SOC is the state of charge, $\delta$ is the self discharge coefficient (almost $.03 \%$ per month), $\mathrm{N}_{\text {batp }}$ is the no. of batteries in parallel, DOD is the Depth of discharge, $\mathrm{C}_{\mathrm{N}}$ is the nominal capacity. In this project we have considered lead-acid batteries with ratings as $200 \mathrm{Ah}, 12 \mathrm{~V}$.

The number of discharge-charge cycles the battery can experience before it fails to meet specific performance criteria is called its cycle life. Cycle life is estimated for specific charge and discharge conditions. The actual operating life of the battery is inversely proportional to the rate and depth of cycles and by other conditions such as temperature and humidity. The higher the DOD, the lower will be the cycle life.

\subsection{Modeling of Electrolyzers}

The rate of gas production is based on the Faraday's law of electro-chemistry. Cathode reaction:

$2 \mathrm{H}_{2} \mathrm{O}(\mathrm{l})+2 \mathrm{e}^{-} \rightarrow \mathrm{H}_{2}(\mathrm{~g})+2 \mathrm{OH}^{-}(\mathrm{aq})$

Anode reaction:

$2 \mathrm{OH}^{-}(\mathrm{aq})=\frac{1}{2} \mathrm{O}_{2}(\mathrm{~g})+\mathrm{H}_{2} \mathrm{O}(\mathrm{l})+2 \mathrm{e}^{-}$

Hydrogen produced by each cell is given by the as [22]:

$\mathrm{H}_{2}(\mathrm{lt})=\left(\mathrm{i} * \mathrm{t} * 22.4 * \eta_{\mathrm{F}}\right) /(96485.30 * 2)$

The electrolysis process is not $100 \%$ efficient due to leakage current loss through cells and electrolyte circulation channels resulting in heat production. The Faraday's efficiency is often known as current efficiency. Proper modeling of Faraday's efficiency is important for accurate prediction of gas production rate. In this project the Faraday's efficiency has been assumed to be between $92 \%$ and $98 \%$ [22]. However, Empirical equations such as (20) can also be used to predict the faraday's efficiency as follows:

$\eta_{F}(\%)=a 1 \cdot \exp \left(\frac{22+a 3 T+a 4 T^{2}}{(i / A)}+\frac{a 5+a 6 T+a 7 T^{2}}{(i / A)^{2}}\right)$

$\mathrm{T}$ is the temperature of operation and can be obtained from a detailed simulation, $\mathrm{A}$ is the Taffel's slope, $\mathrm{i}$ is the current supplied to the electrolyzer, a1,a2,... are the coefficients of temperature. For the steady state modeling of the electrolyzer $\mathrm{A}_{\text {elec }}, \mathrm{B}_{\text {elec }}$, parameters have been considered with the equations as follows:

$\mathrm{H}_{2 \text { prod }}$ elec $=\mathrm{A}_{\text {elec }} \cdot \mathrm{P}_{\mathrm{N}_{\_} \text {elec }}+\mathrm{B}_{\text {elec }} \cdot \mathrm{P}$

Where, $A_{\text {elec }}$ (equal to $.025 \mathrm{Kg} / \mathrm{KW}$ ), $B_{\text {elec }}$ (equal to $.1 \mathrm{Kg} / \mathrm{KW}$ ) is the Power coefficients for the electrolyzer, $\mathrm{H}_{2 \text { prodelec }}$ is the amount of hydrogen produced.

\section{PSO Variants Used}

Particle swarm optimization (PSO) was originally introduced by Kennedy and Eberhart in 1995 [23]. It is an evolutionary optimization technique inspired by the social behaviors of bird flocking or fish schooling. In 
PSO, a swarm is defined as a population of interacting elements and a particle is a member in the swarm, representing a potential solution in the search space. However, the performance of PSO is sensitive to its control parameters, such as inertia weight $\mathrm{w}$ and learning factors, $\mathrm{c} 1$ and $\mathrm{c} 2$. The velocity update in normal PSO is given as:

$v_{i}^{j}(t+1)=w \cdot v_{i}^{j}(t)+c_{1} \cdot \operatorname{rand}(0,1)\left(\operatorname{pbest}_{i}^{j}-x_{i}^{j}(t)\right)+c_{2} \cdot \operatorname{rand}(0,1)\left(\operatorname{gbest}^{j}(t)-x_{i}^{j}(t)\right)$

Where, $v_{i}^{j}$ is the velocity of the $i^{\text {th }}$ particle in the $j^{\text {th }}$ dimension, pbest $_{i}^{j} i$ is the pbest is the personal best of the ith particle in the jth dimension, and $c_{1}$ and $c_{2}$ are the local and global cognitive factors and $x_{i}^{j}$ is the position of the $\mathrm{i}^{\text {th }}$ particle in the $\mathrm{j}^{\text {th }}$ dimension.

\subsection{Reset PSO (RPSO)}

RPSO concerns the restarting strategy. Similar to other known algorithms like CHC [24] and G-CMAES [25], our PSO is stopped whenever one stopping criterion described below is met, and a restart is launched. The decision on when to restart the algorithm is made according to two independent criteria:

1. Stop if the standard deviation of the fitness values of particles in the entire swarm is smaller than 1e- 3 and a re-initialization is performed according to (22). Where, $x_{\text {low }}^{j}$ and $x_{\text {upp }}^{j}$ are lower and upper boundaries of the $j$ th dimension.

$x_{i}^{j}(t+1)=x_{l o w}^{j}+\operatorname{randn}(0,1) \cdot\left(x_{\text {upp }}^{j}-x_{\text {low }}^{j}\right)$

2. Stop if the overall change in the objective function value is below 1e-8 for $10 . \mathrm{DIM} / \mathrm{size}$ iterations. In this case, the particles are re-initialized by calculating their differences to the global best position gbest ${ }^{\mathrm{j}}(\mathrm{t})$ and then dividing them by two. This way, we force the particles to go to the best but avoiding the global convergence at a local minima.

$\mathrm{x}_{\mathrm{i}}^{\mathrm{j}}(\mathrm{t}+1)=\left(\operatorname{gbest}^{\mathrm{j}}(\mathrm{t})-\mathrm{x}_{\mathrm{i}}^{\mathrm{j}}(\mathrm{t})\right) / 2$

The first restarting criteria, prevents stagnation of the algorithm especially in case of multi-modal functions. The second restarting criterion helps the algorithm to escape plateaus and regular regions in functions like Rosenbrock, Schwefel, and their hybrids. Useful time and computational resource are wasted by unnecessary and fruitless function evaluations in these regions.

\subsection{APSO}

In PSO, there are three parameters, w, c1, c2, which highly determine its performance. For the inertia weight $\mathrm{w}$ a linearly decreased value is beneficial for improving the performance of PSO [26]. Here the inertia weight is updated as follows:

$\mathrm{w}=\mathrm{w}_{1} \mathrm{e}^{-\mathrm{gen} / \mathrm{max} \text { igen }}$

$\mathrm{w}_{1}=\mathrm{w}_{\text {high }}-\left(\mathrm{w}_{\text {high }}-\mathrm{w}_{\text {low }}\right) \cdot \frac{\text { gen }}{\max \text { 鸮gen }}$

Where, gen is the index of generation, max_gen is the maximum number of generations, and $w_{\text {low }}, w_{\text {high }}$ are predefined boundary values. In this paper, $\mathrm{w}_{\text {low }}$ and $\mathrm{w}_{\text {high }}$ are set to 0.4 and 0.9 , respectively. Now, to dynamically adjust these factors, we use a self-adaptive mechanism. According to the suggestions of [27], $\mathrm{c} 1$ is self-adjusted as follows.

$$
\begin{aligned}
& c_{1 \mathrm{i}}=\mathrm{c}_{\text {high }}-\left(\mathrm{c}_{\text {high }}-\mathrm{c}_{\text {low }}\right) \text { score }_{\mathrm{i}} \\
& \text { score }_{i}= \begin{cases}\frac{f\left(\text { pbest }_{w}\right)-f\left(\text { pbest }_{i}\right)}{f\left(\text { pbest }_{w}\right)-f\left(\text { gbest }^{\prime}\right)} & \text { if } f\left(\text { pbest }_{w}\right)>f(\text { gbest }) \\
1, & \text { otherwise }\end{cases}
\end{aligned}
$$

Where, the worst particle among all previous best particles is pbest ${ }_{w}$, and $c_{\text {low }}$ and $c_{\text {high }}$ are two predefined lower and upper bounds. For each particle $i$, there is an independent $c 1 i$. The values of $c_{\text {low }}$ and $c_{\text {high }}$ severely affect the performance of the algorithm[28]. Empirical studies show that $c_{\text {low }}$ is set to 0.5 , whereas $c_{\text {high }}$ is linearly decreased from 2.5 to 0.5 to guarantee the convergence in the latter evolutionary stage. For the factor c2, a linearly increased method is used as follows. 
$c_{2}=c_{\text {low }}+\left(c_{\text {high }}-c_{\text {low }}\right) \frac{\text { gen }}{\text { max }}$

\section{Iterative Procedure and verification of results from PSO}

\subsection{Calculation of judgment parameters}

Considering the techno - economic nature of the problem, reliability and per unit cost are considered as the apt parameters for optimal sizing. EENS (Expected value of energy not served) represents the reliability of the system and ranges from 0 to 1 indicating complete reliability and complete unreliability respectively. Per unit cost gives us the cost of 1 unit of energy.

EENS for a combination is given as:

$\mathrm{EENS}_{\mathrm{nc}}=\frac{\sum_{1}^{8760} \mathrm{ENS}}{\text { Total load }}$

Where,

ENS $=\operatorname{Load}(\mathrm{t})-$ Total Generation $(\mathrm{t})$

Per unit cost is calculated as in Eqn. (26)

Perunitcost $(\$ / \mathrm{KWh})=\frac{\sum_{\mathrm{k}=1}^{5}\left(\left(\mathrm{I}_{\mathrm{k}}-\mathrm{S}_{\mathrm{k}}\right) \cdot \mathrm{D}_{\mathrm{k}}+0 \& M_{\mathrm{k}} \text {.Ratedcapacity }\right)}{\mathrm{N} *(\text { Total Load })}$

where, nc is the no. of combinations, ENS is the Energy not supplied, EENS is the Expected value of Energy not supplied, $\mathrm{I}^{\mathrm{k}}$ is the initial cost of the $\mathrm{k}^{\text {th }}$ component, $O \& \mathrm{M}_{\mathrm{k}}$ is the Operation and maintenance cost for the $\mathrm{k}^{\mathrm{th}}$ component, $\mathrm{S}_{\mathrm{k}}$ is the Salvage cost $\mathrm{k}^{\text {th }}$ component, $\mathrm{D}_{\mathrm{k}}$ is the number of times the equipment has been replaced, $\mathrm{N}$ is the total number of years for the paper, $\mathrm{P}_{\mathrm{M}}$ is the maximum power.

\subsection{Formulation of a single objective function}

A combination is chosen as the best combination by equally compromising both objectives. Since the ideal value of reliability (EENS) should be zero and the ideal value of per-unit cost (pucost) should be zero, the problem can be reduced to a single objective optimization problem by framing the problem or objective function as in (32):

$\mathrm{f}=\sqrt{\mathrm{f}_{1}^{2}+\mathrm{f}_{2}^{2}}$

where, $\mathrm{f}_{1}=$ EENS and $\mathrm{f}_{2}=$ pucost

Various types of objective functions have been tested for accuracy among which (32) has been found to give most accurate results. The accuracy of the results has been verified by comparing it to that of an iterative procedure. For a wind/PV/fuel cell system the optimal sizing has been done iteratively first and then an objective function has been developed for PSO. The results of various objectives functions have been compared with the results of the iterative method.

The following constraints have been obeyed during optimization:

$$
\begin{gathered}
\mathrm{NWT}_{\text {min }}<\mathrm{NWT}<\mathrm{NWT}_{\text {max }} \\
\mathrm{NPV}_{\text {min }}<\mathrm{NPV}<\mathrm{NPV}_{\text {max }} \\
\mathrm{Nbat}_{\text {min }}<\mathrm{Nbat}<\mathrm{Nbat}_{\text {max }} \\
\mathrm{NF}_{\text {min }}<\mathrm{NF}<\mathrm{NF}_{\text {max }} \\
\mathrm{DOD}_{\text {min }}<\mathrm{DOD}<\mathrm{DOD}_{\text {max }} \\
\mathrm{VH}_{\text {min }}<\mathrm{VH}<\mathrm{VH}_{\text {max }}
\end{gathered}
$$

\subsection{Deriving results from iterative procedure}

An iterative procedure has been initially used to decide the optimality of a configuration where iterations have been carried out by prioritizing the equipment to be incremented. The costliest equipment i.e., fuel cells are incremented at the end, whereas the cheapest equipment i.e., solar panels are incremented first, and Fig. 2 is obtained.

Fig. 2 displays three fronts that consist of points indicating the reliability and per-unit cost of each combination of sources (Wind/PV/Fuel cell). Each front is generated with the increase in the number of fuel cells by one. In order to derive the results from the scatter plot a trade off is carried out between the cost and the reliability where each parameter is compromised to a certain degree. Here both parameters are equally compromised and thus the most optimal point occurs nearest to the origin and at the knee of the curve. 
Increasing the dimensions would result in the increase in the number of points which would make it very complicated to choose the optimal point manually.

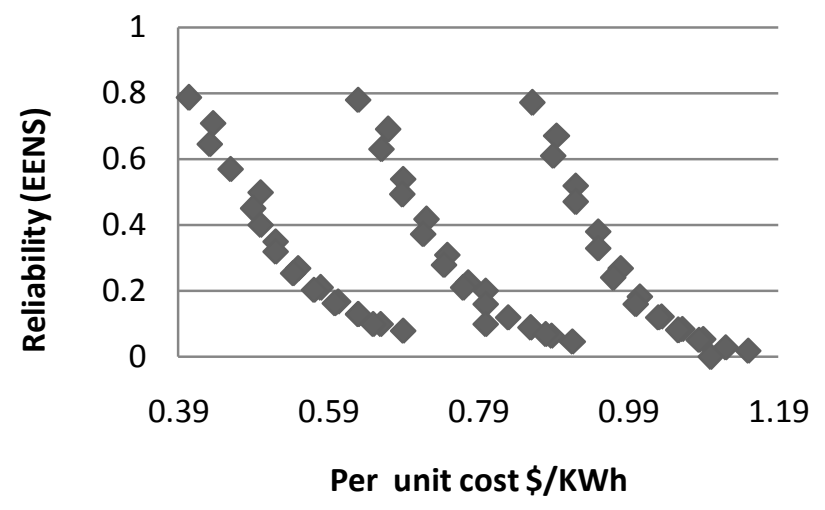

Figure 2. Scatter plot depicting the results of the iterative method

As mentioned before a number of functions have been compared. Finally the distance function has been confirmed. Table 2 displays the results of use of different types of objective functions for optimal sizing.

Table2. Comparison of results from iterative method and PSO to select the objective function

\begin{tabular}{|l|l|l|l|l|l|}
\hline $\begin{array}{l}\text { Type of Objective } \\
\text { Function }\end{array}$ & NPV*2 & NWT & NFC & EENS & Per-unit cost \\
\hline $\begin{array}{l}\text { Results from iterative } \\
\text { procedure }\end{array}$ & 58 & 2 & 1 & .14 & .55 \\
\hline $\begin{array}{l}\text { Results from PSO } \\
\text { distance function }\end{array}$ & 58 & 2 & 1 & .14 & .55 \\
\hline $\begin{array}{l}\text { Results from PSO } \\
\text { weighted sum function }\end{array}$ & 55 & 2 & 2 & .13 & .79 \\
\hline
\end{tabular}

Swarm() is a three - dimensional vector in which all the properties of a particle are stored. Including all properties of a particle in a single vector reduces the length of the code. The first dimension is the particle number, the second dimension is the particle property and the third dimension is the dimension of search. Table 3 displays the vectorisation strategy that is used for both normal PSO and APSO/RPSO.

Table3. Vectorisation strategy for all variants of PSO

\begin{tabular}{|l|l|l|l|}
\hline Name of vector & Particle number & Particle property & Particle dimension \\
\hline & & & $1-\mathrm{NWT}$ \\
& & & $2-\mathrm{NPV}$ \\
& & $1-$ position & $3-\mathrm{NF}$ \\
Swarm() & $1,2,3,4 \ldots \ldots$ & $4-$ velocity & $5-\mathrm{VH}$ \\
& & $3-$ pbest & $5-\mathrm{DOD}$ \\
& & $4-$ gbest & $6-$ SOC $\alpha$ \\
& & 7 to $19-$ Monthly power split \\
& & & parameters $(\alpha)$ \\
\hline
\end{tabular}

V. Energy management strategy for hybrid wind/PV/battery/FC system

Fig. 3 describes the energy management strategy that has been designed. An energy management strategy is the fundamental aspect of a hybrid energy system as it controls the system, maintains the health of power sources and selects modes to enhance the reliability and economy of the entire system. Five modes of operation have been created to improvise the optimal working of the entire configuration. The five modes are as follows: a) Battery mode b) Fuel cell mode c) Fuel cell recharge mode d) Hybrid mode and e) Renewable recharge mode.

Battery mode is where renewable sources and the batteries suffice the load completely, provided the initial SOC of the battery bank is higher than SOC $\alpha$, after SOC $\alpha$ the hybrid mode commences and PEMFC works along with the battery to suffice the load. The power split parameter $\alpha$ is decided on a monthly basis and is derived from optimal sizing. In case the initial SOC of the battery bank is bellow $\mathrm{SOC}_{\min }$ the fuel cell mode commences. Now, the power deficit may be above maximum efficiency power of the fuel cell or below it. When the power deficit is below maximum efficiency power of the fuel cell, the Fuel cell is run at maximum efficiency and excess power from the fuel cell is used to recharge the battery bank. The renewable recharge mode is where the renewable sources generate excess power and thus not only supply the load but also charge the batteries and run the electrolyzer. 


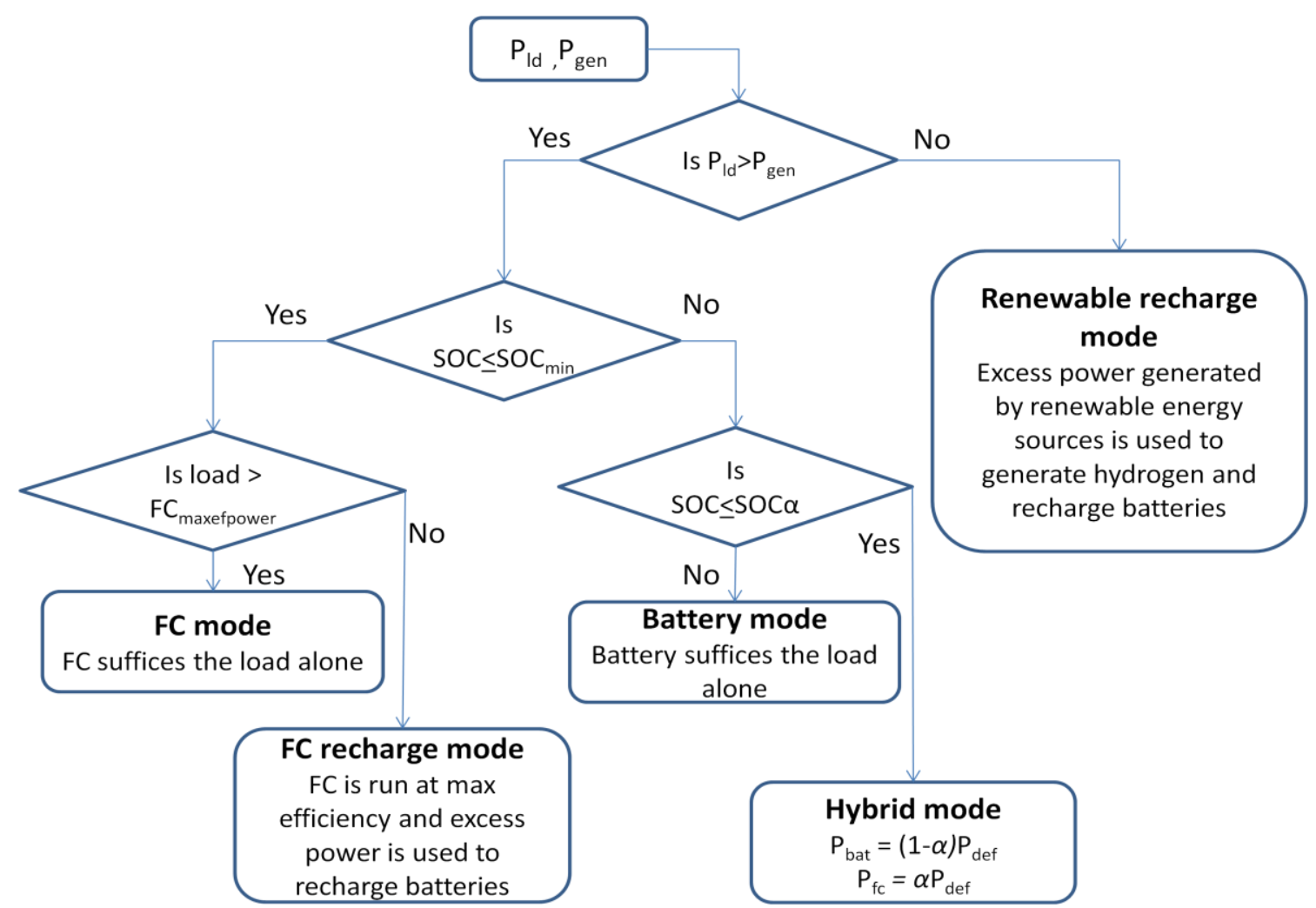

Fig. 3. The energy management strategy

\section{Neural prediction of total life of battery and FC}

Neural networks are mathematical approximations of the brain cells and consist of neurons that function like biological neurons and represent them graphically. They constitute the bundle of nerves that are interconnected in the brain and are connected through a complicated mesh. Radial basis function networks are better than feed-forward neural networks when function approximation is to be performed.

\subsection{NNFCLIFE and NNBATLIFE}

Voltage degradation at the terminals of the device is the main indicator of life of device. The life of a PEMFC is affected by factors like polymer degradation, de-lamination, starvation, reverse currents, catalyst dissolution and Carbon oxidation [29]. Most of the degrading phenomenon occurs during the start-up and shutdown of the device. Kurt. J. et. Al [30] provides a detail analysis of terminal voltage degradation with operational time. Flower. M. [31], also describes the failure of a PEMFC with a, "Bathtub curve". To generate the training data set, the fuel cell is simulated under varying load conditions for different operating periods and for a number of cycles $[30,19]$. The rate of degradation of voltage has been observed matched with the corresponding works of Flower. M. [31] to obtain the respective total life. Fig. 4 depicts the structure of NNFCLIFE which is used to predict the life of the fuel cell in terms of hours of operation under certain operating conditions. Apart from that data has also been taken from the data sheet of Hydrogenics fuel cell. The life of fuel cells and batteries predicted by the NNBATLIFE and NNFCLIFE are used to calculate the replacement frequency or $\mathrm{D}^{\mathrm{k}}$. The effect of $\mathrm{D}^{\mathrm{k}}$ is included in the economic aspect and is thus taken care of by optimal sizing. NNFCLIFE has 3 neurons in the input layer, 5 neurons in the hidden layer that implement a radial basis function, and one output neuron in the output layer that executes a purelin function. 


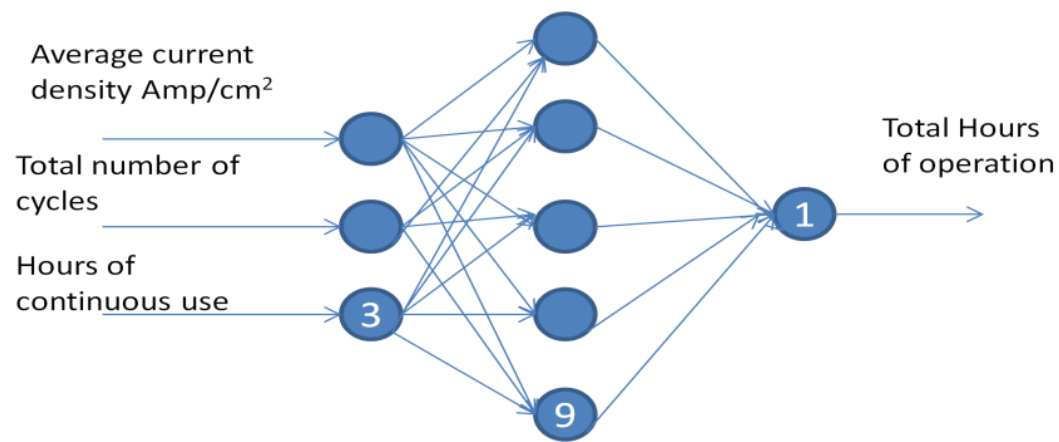

Figure 4. NNFCLIFE radial basis function network

Fig. 5 depicts the input model and structure of NNBATLIFE. NNBATLIFE has been obtained primarily from battery data sheets and from detailed model simulations as in [20, 21]. The no. of cycles can easily be obtained from the user manuals of standard lead acid batteries as is used here. For the purpose of our work we considered Tempest 120, 150 and 200Ah batteries. The cycles are further affected by the working temperature of the battery which can be estimated from the detailed simulation model and correspondingly a derating factor can be assigned as per the net electrolyte density. NNBATLIFE consists of 3 layers: input layer, hidden layer and output layer. The input layer does not perform any mathematical function. The hidden layers execute a radial basis function of the weighted sum of inputs. The output neuron executes the purelin function of the weighted sum of its input.

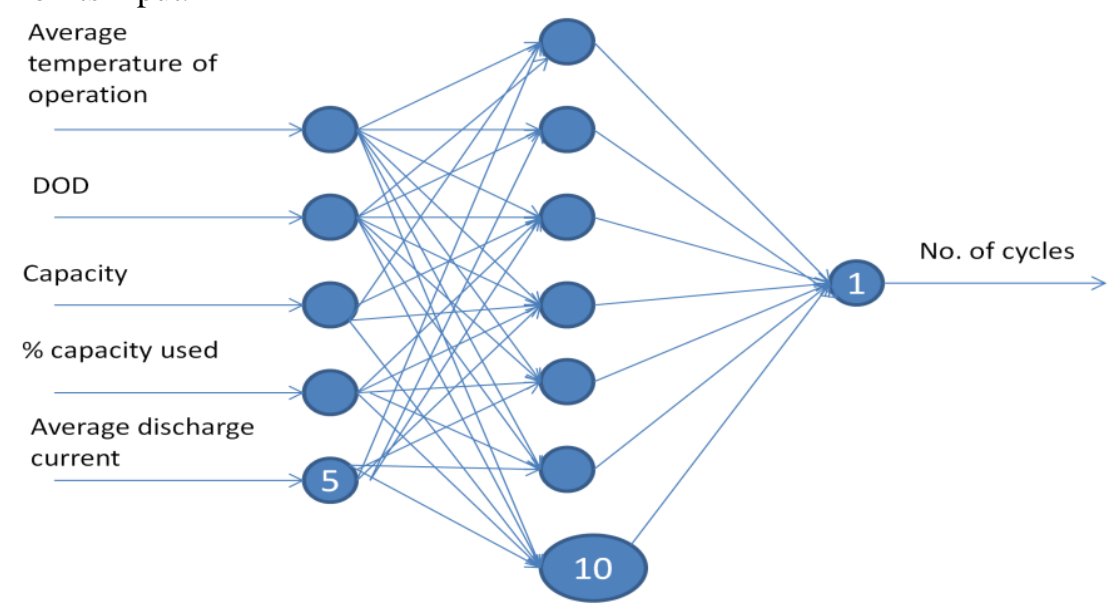

Figure 5. NNBATLIFE radial basis function network

\subsection{Training}

For the training of two neural nets, two variants of PSO (RPSO and APSO) have been compared again. The two networks are radial basis function networks and the various dimensions for RPSO and APSO are the weights connecting the input layer and hidden layer, the mean of each hidden neuron, the standard deviation of each hidden neuron, the weights connecting the hidden neurons and the output neuron, the slope of the purelin function of the output neuron and the biases for each hidden neuron. Limits have not been imposed on any dimension as it has been observed to give a better MSE. MSE or mean square error has been considered as the fitness function.

$$
\text { MSE }=\frac{\sum_{i=1}^{N} \text { output }_{i}-\text { target }_{i} \mid}{N}
$$

MSE indicates the accuracy of regression that can be performed by the network and here the network is trained until MSE dropped to $1 \mathrm{e}-3$. Where, output $\mathrm{i}_{\mathrm{i}}$ is the desired $\mathrm{i}^{\text {th }}$ output, target $\mathrm{i}_{\mathrm{i}}$ is the target of the $\mathrm{i}^{\text {th }}$ data set and $\mathrm{N}$ is the total number of data sets.

\section{Optimization algorithm}

The optimization algorithm is very simple and is quite similar to that of the iterative algorithm. The optimization algorithm generates random combinations and approaches towards the most suitable combination unlike the iterative combination, where, the combinations are generated in a particular order. This combination is then tested for a period of 8760 hours. For every combination the inputs to the RBFNs have been determined after 8760 hours operational data has been gathered. Using the life of the equipments for those particular working conditions from the NNBATLIFE and NNFCLIFE, the replacement frequency is calculated. For every 
combination, reliability and per unit cost are calculated using (30) and (32). Finally to judge the optimality of the combination (33) is evaluated.

\section{Results}

The results of optimal sizing, training of neural networks and the optimized monthly parameters have been discussed in this section. The solar radiation data in Fig. 6, wind speed data in Fig. 7, and the temperature data in Fig. 8, considered for optimal sizing has been taken for Kolkata $\left(22.57^{\circ} \mathrm{N}, 88.37^{\circ} \mathrm{E}\right)$.

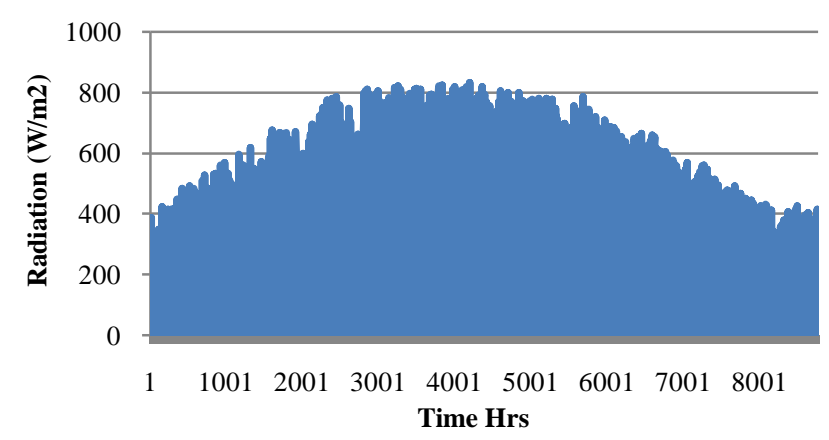

Figure 6. Solar radiation data

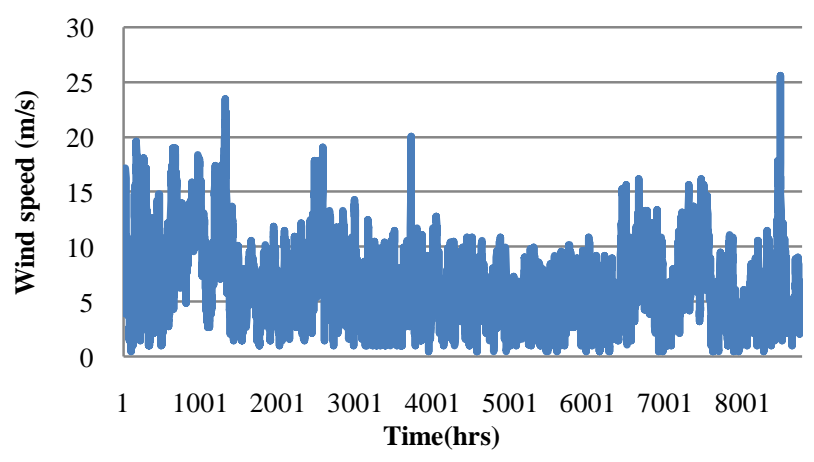

Figure 7. Wind speed data

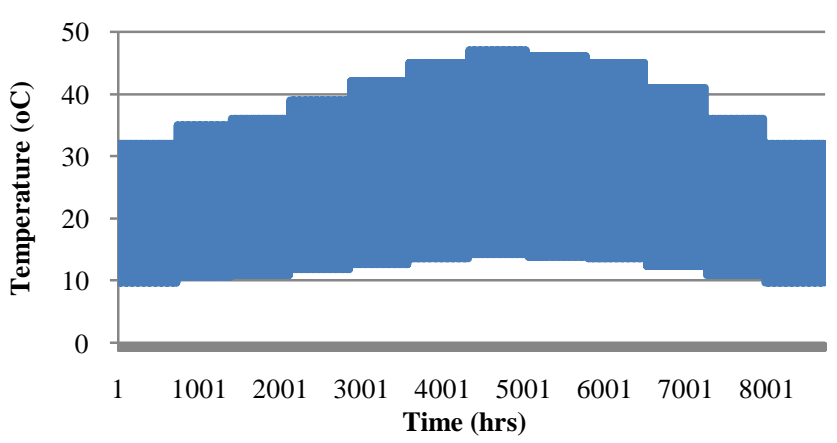

Figure 8. Temperature data

The load profile that has been considered in this work, displayed in Fig. 9, is a standard IEEE load profile [32] for domestic loads with a peak of 2.1pu and an average of $1 \mathrm{pu}$. The peak arises after $1930 \mathrm{hrs}$ in the evening, while decreases to $.5 \mathrm{pu}$ during $2300 \mathrm{hrs}$ to $500 \mathrm{hrs}$ which coincides with the daily routine of common people. A major difference between industrial and domestic load or a favorable consequence is that the solar profile coincides with that of the load but for the domestic load we have the wind profile coinciding with that of load. 


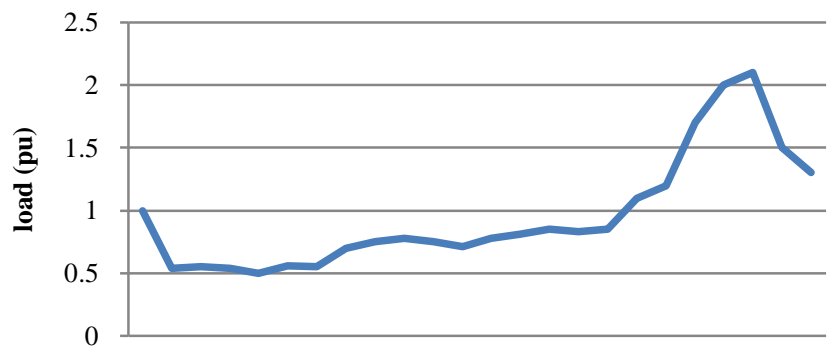

Time (Hrs)

Figure 9. Daily load profile

Table 4 reports the cost of all the following components. The data in Table 4 has been taken from the references $[1,2,3]$. Such resources can also be obtained from official quotations.

Table4. Cost of components

\begin{tabular}{|l|l|l|l|l|l|}
\hline $\begin{array}{l}\text { Type of } \\
\text { equipment }\end{array}$ & $\begin{array}{l}\text { Rated } \\
\text { capacity }\end{array}$ & $\begin{array}{l}\text { Capital } \\
\text { cost }\end{array}$ & O\&M cost & $\begin{array}{l}\text { Salvage } \\
\text { Cost }\end{array}$ & $\begin{array}{l}\text { Life } \\
\text { Span }\end{array}$ \\
\hline $\begin{array}{l}\text { Wind } \\
\text { turbine }\end{array}$ & $6 \mathrm{KW}$ & $1015 \$ / \mathrm{KW}$ & $25 \$ / \mathrm{KW}$ & $230 \$ / \mathrm{KW}$ & 25 years \\
\hline $\begin{array}{l}\text { Solar } \\
\text { panels }\end{array}$ & $200 \mathrm{~W}$ & $4401 \$ / \mathrm{KW}$ & $88.01 \$ / \mathrm{KW}$ & $880 \$ / \mathrm{KW}$ & 20 years \\
\hline Fuel cells & $2 \mathrm{KW}$ & $6000 \$ / \mathrm{KW}$ & $240 \$ / \mathrm{KW}$ & $300 \$ / \mathrm{KW}$ & $15000 \mathrm{hrs}$ \\
\hline Battery & $200 \mathrm{Ah}$ & $200 \$$ & $5 \$$ & $20 \$$ & $\begin{array}{l}400-800 \\
\text { cycles }\end{array}$ \\
\hline Electrolyzer & $2 \mathrm{KW}$ & $3000 \$ / \mathrm{KW}$ & $120 \$ / \mathrm{KW}$ & $150 \$ / \mathrm{KW}$ & 10 years \\
\hline
\end{tabular}

The most optimal configuration has been determined to consist of 2 wind turbines, 41 strings of solar panels, where, each string has two panels in series, 1 PEM fuel cell stack, 24 strings of batteries with each string of two batteries in series and one electrolyzer. The hydrogen storage capacity should be $2.966 \mathrm{Kg}$ and the batteries should be discharged to a limit of $71 \%$. The base load of the system has been taken as $12 \mathrm{KW}$ and the peak of $25.2 \mathrm{KW}$ and the load type under consideration is domestic. The per unit cost of this combination falls within a range of $31.08 \mathrm{c} / \mathrm{KWh}$ to $32.88 \mathrm{c} / \mathrm{KWh}$.

Discount on equipment cost has not been considered as the purchased amount is small. Two important component are required along the equipments purchased: a) Hybrid power controller with a rated capacity of 25 KW, which performs wind and solar MPPT and gives a DC output which usually costs around 20,000\$ and b) an inverter with rated capacity of 30KVA which costs around $3000 \$$. These costs have been added to the initial cost and have been included for the calculation of per unit cost.

Table5. Power split parameters obtained from optimal sizing on a monthly basis

\begin{tabular}{|l|l|l|l|l|l|l|l|l|l|l|l|}
\hline Jan & Feb & Mar & Apr & May & Jun & Jul & Aug & Sep & Oct & Nov & Dec \\
\hline .65 & .59 & .51 & .45 & .48 & .43 & .41 & .47 & .48 & .45 & .51 & .59 \\
\hline
\end{tabular}

Table 5 displays the optimal values of the monthly power split parameters that have been obtained from optimal sizing. Results of optimal sizing have been displayed on a comparative basis where the effect of increase in design variables has been observed. The initial cost constraint proved its importance as the reliability of the initial case could be enhanced by only $2 \%$ but with a $12 \%$ increase in initial cost.

Table6. Results of optimal sizing and depiction of increase in number of variables of search

\begin{tabular}{|l|c|c|c|c|c|c|c|c|}
\hline \multicolumn{1}{|c|}{$\begin{array}{c}\text { Design } \\
\text { Variables }\end{array}$} & NWT & NPV*2 & NF & NBAT*2 & DOD & VH & RELIABILITY & $\begin{array}{c}\text { PUCOST } \\
\text { (\$/Kwhr) }\end{array}$ \\
\hline $\begin{array}{l}\text { NWT, } \\
\text { NPV,NF,VH }\end{array}$ & 2 & 50 & 1 & 0 & 0 & $\begin{array}{c}9.375 \\
\text { (optimized) }\end{array}$ & .12 & .518 \\
\hline $\begin{array}{l}\text { NWT, NPV,NF, } \\
\text { NBAT,VH }\end{array}$ & 2 & 43 & 1 & 28 & $\begin{array}{c}.65 \\
\text { (fixed) }\end{array}$ & $\begin{array}{c}3.76 \\
\text { (optimized) }\end{array}$ & .005 & .553 \\
\hline $\begin{array}{l}\text { NWT, NPV,NF, } \\
\text { NBAT,VH, } \\
\text { DOD }\end{array}$ & 2 & 41 & 1 & 24 & $\begin{array}{c}.71 \\
\text { (optimized) }\end{array}$ & $\begin{array}{c}2.966 \\
\text { (OPTIMIZED) }\end{array}$ & 0.00076 & 0.548 \\
\hline
\end{tabular}




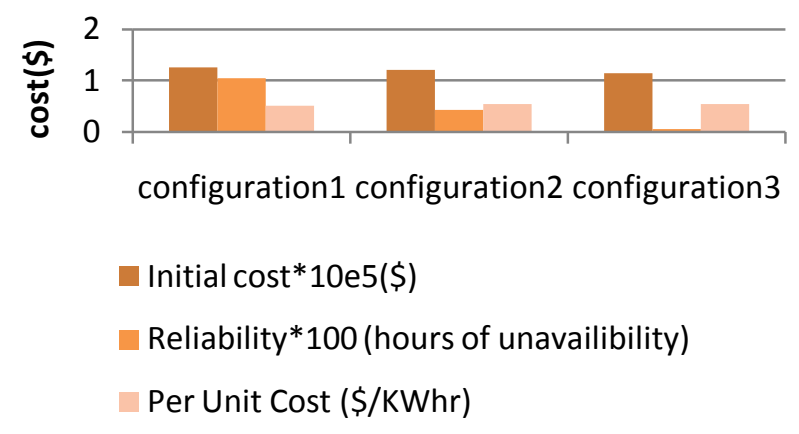

Figure 10. Case wise analysis for all three configurations

Table 6 displays a comparative analysis of the entire system where the first configuration excludes batteries, the $2^{\text {nd }}$ configuration includes batteries but does not optimize DOD and the final configuration optimizes the entire system including battery DOD. Fig. 10 displays the benefits of the optimized configuration over the other configurations in a graphical manner, where we realize that with a $9.95 \%$ reduction in the initial cost, reliability has been enhanced by $94 \%$. The main reason behind this is the inclusion of batteries. Next, by optimizing the DOD of batteries (with a $9.23 \%$ increase), the initial cost has been reduced by $5.35 \%$.

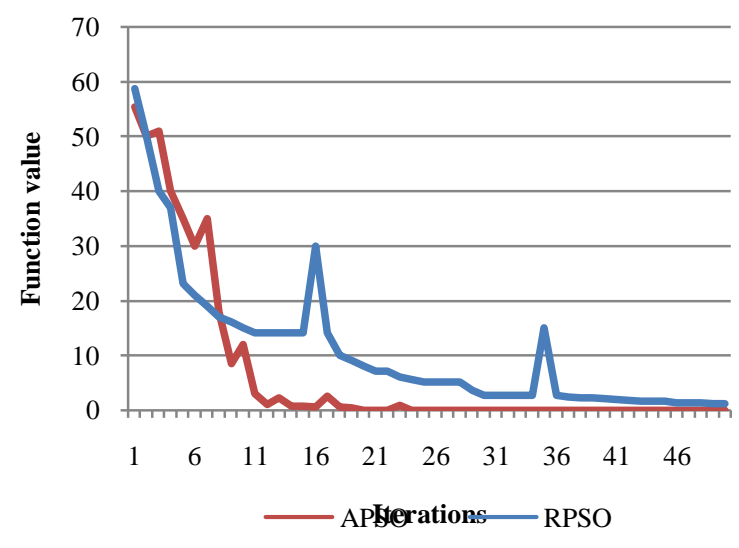

Figure 11. Optimization curve for Neural Network Training

Fig. 11 displays the optimization curve for neural network training. APSO is more efficient in overcoming the tendency of getting diverted to local minima. APSO not only gives us a better function value but also gives us quicker convergence and the standard deviation of particle function value is also less as compared to that of RPSO. The training of a radial basis function network is a problem with very high dimensions and a complex search space with high degree of multimodality. With the increase of one neuron in the hidden layer the number of dimensions increases by three. Although the RBFN has a higher dimensionality it has been found that it is easier to train in terms of MSE and the total time required for training.

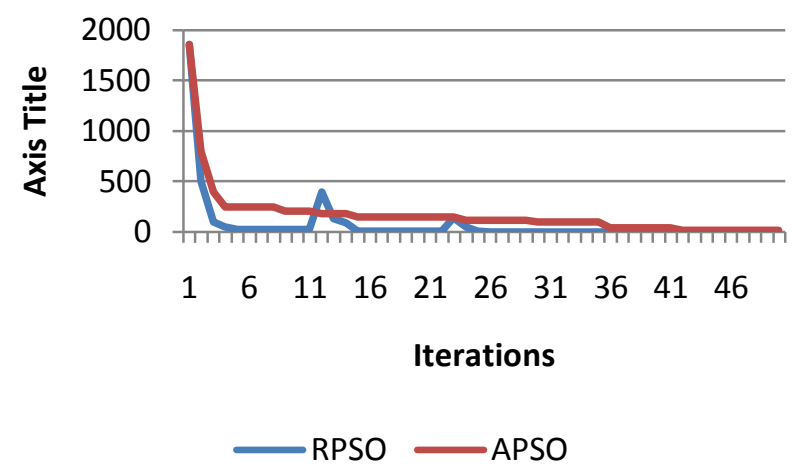

Figure 12. Optimization curve for Optimal sizing 
Fig. 12 displays the optimization curve for optimal sizing. Optimal sizing is a problem with low dimensionality but a large search space and regular regions. The degree of multimodality is also less and that allows us to get comparatively smooth pareto-fronts even if we perform multi-objective optimization.

\section{Conclusion}

In this paper optimal sizing of a wind/PV/fuel cell/battery system has been performed using APSO and the use of a new energy management strategy has been presented for the hybrid system. EENS and per unit cost are the two parameters that have been used to judge the optimality of a configuration. The design variables that have been considered for optimal sizing are: no. of wind turbines, no. of PV panels, no. of fuel cells, no. of batteries, volume of hydrogen and, DOD of batteries, monthly power split parameters and SOC set point for hybrid mode operation.

The energy management strategy uses monthly power split parameter called $\alpha$, to facilitate the division of load between batteries and fuel cells after a certain SOC set point is reached. The optimization strategy also incorporates a couple of RBF neural networks which decide the operational life of the PEMFC and the battery. This helps the algorithm to maintain healthy operating conditions for both batteries and PEMFCs. Five modes of operation have been created for the energy management strategy: a) Battery mode b) Fuel cell mode c) Fuel cell recharge mode d) Hybrid mode and e) Renewable recharge mode.

Initially, a wind/PV/fuel cell system has been considered and optimized using an iterative method and this has been done in order to design an objective function for the problem to be solved with PSO. Here the requirement of an evolutionary algorithm has been realized due to the complexity of manually finding a solution from the iterative method in case the number of search dimensions increased above 3. APSO has been coded and used to solve the problem and the results have been compared to the RPSO. RPSO was used to train the RBFNs.

Finally, a comparison has been done between three cases and the advantages of optimizing each dimension and using the innovative energy management strategy have been realized. MATLAB coding has been used to simulate the power sources and the energy management strategy and test each combination for a period of 8760 hours configuration has been used for optimal sizing, which results in an economic as well as technically reliable combination.

\section{Acknowledgement}

We would like to take this opportunity to thank my guide Mrs. D. Suchitra who has been extremely helpful with her bountiful knowledge, her extremely valuable time and concern. She has played a key role in every part of this paper and without her effort completion of this article would not have been possible. We also thank our HOD, Dr. Vijay Kumar, of our EEE department (SRM University) who has been ever supportive and has played a key source of encouragement.

\section{References}

[1] Yiannis A. Katsigiannis et-al, "Hybrid Simulated Annealing-Tabu Search Method For Optimal Sizing Of Autonomous Power Systems With Renewable", IEEE transactions on sustainable energy, Vol.3, No.3, July 2012.

[2] Daming Xu et-al; "Optimal sizing of standalone hybrid wind/PV power systems using genetic algorithms"; IEEE Canadian Conference Electrical and Computer Engineering, 2005.

[3] Eftichios Koutroulis et-al; "Methodology for optimal sizing of stand-alone photovoltaic/ wind generator systems using genetic algorithms"; Elsevier Solar Energy Journal, Vol. 80, Issue 9.

[4] Dalton, G.J., Lockington, D.A., Baldock, T.E., 2009. "Case study feasibility of renewable energy supply options for small to medium size tourist accommodations”. Renewable Energy 34 (4), 1134-1144.

[5] Belfkira, R et-al; "Optimal sizing of a stand-alone hybrid wind/PV system with battery storage”, IEEE European Conference Power Electronics and Applications, 2007.

[6] Jidong Wang et-al, "Optimal capacity allocation of standalone wind/pv/battery hybrid power system based on an improved particle swarm algorithm”. IET Renewable Power Generation, March 2013.

[7] Eiben, A. E. et al (1994). "Genetic algorithms with multi-parent recombination used for optimal sizing of a standalone wind/PV system". PPSN III: Proceedings of the International Conference on Evolutionary Computation. The Third Conference on Parallel Problem Solving from Nature: 78-87.

[8] Toshiro Hirose , "Standalone Hybrid Wind-Solar Power Generation System Applying Dump Power Control Without Dump Load", IEEE transactions on industrial electronics, vol. 59, no. 2, february 2012.

[9] Yiannis A. Katsigiannis et-al, "Hybrid Simulated Annealing-Tabu Search Method For Optimal Sizing Of Autonomous Power Systems With Renewable", IEEE transactions on sustainable energy, Vol.3, No.3, July 2012.

[10] Benhachani, Z et-al. "Optimal Sizing Of A Solar-Wind Hybrid Farm Supplying A Farm In A Semi - Arid Region In Algeria". Universities Power Engineering Conference (UPEC), 2012 47th International

[11] Yang, H., Zhou, W., Lou, C., "Optimal design and techno-economic analysis of a hybrid solar-wind power generation system. Applied Energy 86 (2), 2009, 163-169.

[12] Ylmaz, P., Hakan Hocaoglu, M., Konukman, A.E.S., 2008. "A prefeasibility case study on integrated resource planning including renewables. Energy Policy 36 (3), 1223-1232"

[13] Diaf, S. et al., 2008. "Design and techno-economical optimization for hybrid PV/wind system under various meteorological conditions". Applied Energy 85 (10), 968-987. 
[14] K.J.Runtz, et-al. "Fuel Cell Equivalent Circuit Models For Passive Mode Testing and Dynamic Response". IEEE conference CCGEI, May 2005.

[15] Christina Honsberg and Stuart Bowden , "www. Pveducation .org"

[16] J.Zorilla Casanova et - al. "Effect of Dust losses in Photovoltaic modules". World Renewable energy congress, Sweden 2011.

[17] Hussein et-al, "Effect of dust deposition on the performance of multi-crystalline Photovoltaic modeules based on experimental Measurements", IJRER, Vol 3 No. 4, 2013.

[18] Lin Xu, ; Xinbo Ruan ; Chengxiong Mao ; Buhan Zhang "An improved optimal sizing method for wind-solar-battery hybrid power system", IEEE transactions on sustainable energy, 2013.

[19] Souleman et-al. "A Generic Fuel Cell Model For Simulation of Fuel Cell Power Systems". IEEE renewable energy conference Canada, 2009.

[20] Bingjun Xiao, et-al, “A universal state of charge algorithm for batteries”, Electrical Engineering Dept., University of California, Los Angeles, DAC'10, 2010 June 13-18.

[21] Tremblay O, et-al, "A generic battery model for dynamic simulation of hybrid electric vehichles", IEEE transactions on electric vehicles, 2007, Vol. 1, $284-289$.

[22] "Dynamic and transient modeling of electrolyzers powered by renewable energy sources and cost analysis of electrolytic Hydrogen", Amitava Roy, Doctoral Thesis.

[23] J. Kennedy and R. C. Eberhart. "Particle swarm optimization". In Proceedings of IEEE International Conference onNeural Networks, pages 1942-1948, 1995.

[24] L.J. Eshelman. The CHC adaptive search algorithm: how to have safe search when engaging in nontraditional genetic recombination. In G. Rawlins and M. Kaufmann, editors, Proc. of Foundations of Genetic Algorithms Conf, volume 1, pages 265283,1991

[25] A. Auger and N. Hansen. "A restart cma evolution strategy with increasing population size". IEEE Congress on evolutionary Computation, 2:1769-1776, 2005.

[26] R. Eberhart and Y. Shi. "Comparison between genetic algorithms and particle swarm optimization". Proceedings of The 7th Annual Conference on Evolutionary Programming, 1998.

[27] Y. Shi and R.C. Eberhart. "A modified particle swarm optimizer". Proceedings of the Conference on Evolutionary Computation, pages $69-73,1998$

[28] X. Cai, Z. Cui, J. Zeng and Y. Tan. "Particle swarm optimization with self-adjusting cognitive selection strategy". International Journal of Innovative Computing, Information and Control, 4(4):943-952, 2008.

[29] Flower. M, et.al, "Degradation and reliability analysis of PEM fuel cell stack", University of Waterloo.

[30] Jenifer. K, et.al, "Analysis of real world fuel cell degradation", NREL Department of Hydrogen teachnology, Dec 8, 2009, Alexandria

[31] Hui Li, et.al, "A review on performance degradation of proton exchange membrane fuel cells during start up and shut down processes: Causes, consequences and mitigation strategies". Elsevier Journal of Power sources.

[32] Jose.A.J, Tahan.M.V., Gouvea.M.R, "Daily load profiles for residential, commercial, and Industrial low voltage consumers". IEEE transactions on power delivery, Vol. 15, No. 1, January 2000. 